\title{
Clinical Nursing Reasoning in Nursing Practice: A Cognitive Learning Model based on a Think Aloud Methodology
}

\author{
Johanne Goudreau \\ University of Montreal, johanne.goudreau@umontreal.ca \\ Louise Boyer \\ University of Montreal, louise.boyer@umontreal.ca \\ Dimitri Létourneau \\ Université de Montréal, dimitri.letourneau-aspirot@umontreal.ca
}

Follow this and additional works at: https://qane-afi.casn.ca/journal

Part of the Educational Assessment, Evaluation, and Research Commons, and the Other Nursing Commons

\section{Recommended Citation}

Goudreau, Johanne; Boyer, Louise; and Létourneau, Dimitri (2014) "Clinical Nursing Reasoning in Nursing Practice: A Cognitive Learning Model based on a Think Aloud Methodology," Quality Advancement in Nursing Education -

Avancées en formation infirmière: Vol. 1: Iss. 1, Article 4.

DOI: https://doi.org/10.17483/2368-6669.1009

This Article is brought to you for free and open access by Quality Advancement in Nursing Education - Avancées en formation infirmière. It has been accepted for inclusion in Quality Advancement in Nursing Education - Avancées en formation infirmière by an authorized editor of Quality Advancement in Nursing Education - Avancées en formation infirmière. 


\section{Clinical Nursing Reasoning in Nursing Practice: A Cognitive Learning Model}

based on a Think Aloud Methodology

\section{Cover Page Footnote}

This study was funded by a CFHI research grant. 
In the current context of increasingly complex care, clinical reasoning in nursing (CRN) is a core competency that nurses need to extensively develop (American Association of Colleges of Nursing, 2008; Bartels \& Bednash, 2005; National League for Nursing, s. d.; O'Neil \& Pew Health Professions Commission, 1998; Task Force on the Essential Patient Safety Competencies for Professional Nursing Care, 2006; Villeneuve \& MacDonald, 2006). However, a daily observation of practice and an analysis of errors in care settings highlight major difficulties related to CRN, especially in newly graduated nurses (Benner et al., 2002; del Bueno, 2005; Eisenhauer, Hurley, \& Dolan, 2007; Fero, Witsberger, Wesmiller, Zullo, \& Hoffman, 2009; Greenwood, 2000; Woods \& Doan-Johnson, 2002), who need long-term mentoring to reach the required level of competency (Casey, Fink, Krugman, \& Propst, 2004; Duchscher \& Cowin, 2004; Oermann \& Garvin, 2002; Schoessler \& Waldo, 2006a, 2006b; Standing, 2007). More specifically, difficulties have been identified in assessment of health (Duff, Gardiner, \& Barnes, 2007; Thompson et al., 2007) and use of evidence (Andersson, Caderfjäll, Jylli, Kajermo, \& Klang, 2007; Hannes et al., 2007; Profetto-McGrath, 2005). This has been a challenge for nursing educators in the classroom and in the clinical environment, and they are still in need of solid knowledge and tools to support the development of nursing students and RNs' CRN competency. In 2001, the National Research Council (NRC; 2001) suggested that educational programs should be based on a cognitive learning model for each of a program's competencies. According to the NRC (2001) and Tardif (2006), ideally, a cognitive learning model should be developed by relying on empirical research and by identifying developmental stages and the corresponding critical milestones.

In this study, a cognitive learning model of CRN, from the beginning of an education program to clinical expertise, was formulated using the think aloud method. The article contributes to the mission of this new journal, which is to offer new and different perspectives related to the improvement of nursing education.

\section{Background}

Competencies and the concept of cognitive learning models

Consistent with Gonczi's (1996) integrated approach to the concept of competency, Tardif (2006) refers to a competency as a "complex know-act based on the mobilization and combination of knowledge, skills, attitudes and external resources [that is] adequately applied in specific families of situations." (p. 22) Also, the results of a recent analysis of the concept of competency concludes that it "could be defined as a formal action of systemic skills, contextualized and continuously being developed" [name withheld to maintain the integrity of the review process]. Thus, a competency is more holistic and dynamic than the tasks or the skills that underpin it and it is specific to a context. Moreover, a competency is characterized by its potential for development, that is to say it continues to evolve after basic education through experience and continuing education (Tardif, 2006). Therefore, CRN respects these postulates and is considered a competency.

According to Tardif (2006), a cognitive learning model provides a description of the developmental stages of a competency and its critical milestones. The stages of a cognitive learning model are complementary and mutually exclusive, meaning that a learner cannot move on to a further stage without first passing the specific critical milestones of the previous stage. The critical milestones are defined as the integration of new cognitive rules and principles or as 
cognitive reorganizations (Tardif, 2006). In line with the NRC (2001), Tardif (2006) supports the cognitive modeling of competencies in order to maximize learning and evaluation. He suggests that researchers and educators must document learners' transformations at different moments of the learning process to build cognitive learning models for their program's competencies. Ideally, these schematic representations should structure program curricula, educational activities, and evaluations, informing educators of the important benchmarks that will help guide students' learning (NRC, 2001).

\section{CRN as a competency to be included in a cognitive learning model}

Like all professionals, nurses begin to develop their competencies during their initial education, and they continue to develop them throughout their professional lives. CRN is a competency that is at the core of nursing practice because it is behind every judgment and intervention made by all nurses (Victor-Chmil, 2013). As argued by Benner, Sutphen, Leonard, and Day (2010), it is a constant challenge for nurses to make the best decisions for their patients and they often have to reason quickly in acute health situations. As CRN is an essential competency in nursing practice, it should be a central theme throughout the curriculum to ensure its early development (Elizondo-Omanã et al., 2010).

Over the past 25 years, several studies have been conducted to explore CRN. There is a general consensus that it is a complex cognitive process of thoughts and decisions, associated with clinical actions that require cognitive operations such as analysis, evaluation and inference, as well as emotional traits such as curiosity and self-confidence (Fonteyn \& Ritter, 2008; Forsberg, Georg, Ziegert, \& Fors, 2011). In her concept analysis of CRN, Simmons (2010) concludes that it is " a complex process that uses cognition, metacognition, and discipline-specific knowledge to gather and analyze patient information, evaluate its significance, and weigh alternative actions." (p. 1151) The cognitive and metacognitive processes referred to in the above definitions coincide with Banning's (2008) and Victor-Chmil's (2013) definitions of CRN, which also state that it is used to analyze clinical situations through the lens of knowledge and to justify nursing interventions. Still, there is a lack of knowledge about CRN within a developmental and educative perspective.

Over the years, studies have documented clinical reasoning in experts (Grobe, Drew, \& Fonteyn, 1991; Newell \& Simon, 1972; Simmons, Lanuza, Fonteyn, Hicks, \& Holm, 2003) and novices (Adams, 2003; Grobe et al., 1991; Manias, Aitken, \& Dunning, 2004; Shin, 1998), or have compared nurses at various levels of expertise (King \& Clark, 2002), uncovering evidence of differences in CRN, according to the level of expertise. These differences were corroborated in a more recent study by Andersson, Klang, and Petersson (2012). These researchers investigated the CRN of nurses at three levels of expertise: novice (six months to two or three years of clinical practice), experienced (more than three years of clinical practice) and expert (specialized education plus more than five years of clinical practice). The nurses $(n=21)$ participated in group discussions using a fictitious case. The content analysis of the recorded discussions $(n=6)$ shows no significant differences between novice and experienced nurses' CRN, although important ones are highlighted between both the novice and experienced nurses versus the expert nurses. Expert nurses were more hypothesis-oriented than novice or experienced nurses, who were more task-oriented or action-oriented. More specifically, the expert nurses' analysis of the case showed more depth, as they used what Benner (2001) calls "the whole picture" to 
understand the case, to hypothesize, and to plan interventions. On the other hand, the novice and experienced nurses were addressing the case's issues one at a time without a comprehensive perspective, relying instead on routines and protocols for intervention planning. Once again, to design their education programs and strategies, for now, nursing educators can solely rely on descriptions of nurses' CRN at different levels of expertise, but very little is known about its developmental stages and critical milestones.

\section{The Study}

Aim

The aim of the study was to develop a cognitive learning model of CRN, based on the results of a think aloud exercise performed by undergraduate nursing students and RNs. The research objectives were: (1) to determine CRN's developmental stages; and (2) to identify the critical milestones of these stages.

Design

A descriptive design based on the think aloud method was used to generate verbal data on students and nurses' clinical reasoning (Fonteyn, Kuipers, \& Grobe, 1993). Having its theoretical roots in cognitive psychology, think aloud research has been used since the 80s (Ericsson \& Simon, 1980). Described as a method for gathering verbal data from a person performing a complex task (MacNeela et al., 2010; Newell \& Simon, 1972), it was successfully used in several studies to identify the cognitive operations of nurses in various clinical settings (Banning, 2008; Corcoran, Narayan, \& Moreland, 1988; Fonteyn \& Fisher, 1995; Fowler, 1997; Funkesson, Anbäcken, \& Ek, 2007; Göransson, Ehnfors, Fonteyn, \& Ehrenberg, 2008; Greenwood, Sullivan, Spence, \& McDonald, 2000; Grobe et al., 1991; MacNeela et al., 2010; Simmons et al., 2003).

\section{Participants}

A convenience sample of RNs and nursing students with different levels of academic and clinical expertise was purposely used in order to elucidate the developmental stages of CRN (Burns \& Grove, 2009). Nursing students from a six-semester long baccalaureate program at a Canadian university were invited to enroll in the study through their academic email. To be eligible, students needed to have successfully completed the second semester (first group, $\mathrm{n}=14$ ), the fourth semester (second group, $n=14$ ), or be at the end of the sixth semester (third group, $n=13$ ). RNs were recruited from two hospitals affiliated with the university where the nursing students were enrolled. An invitation to participate was enclosed with their pay stubs. To be eligible, RNs needed clinical experience of either 12 to 18 months (fourth group, $n=11$ ) or more than 5 years (fifth group, $n=14$ ). The amount of clinical experience needed in the fourth group was chosen in order to study the development of CRN during the critical transitional stage of newly graduated nurses (Chernomas, Care, McKenzie, Guse, \& Currie, 2010; Duchscher, 2008, 2009; Dyess \& Sherman, 2009; Hansen, 2008; Kramer, 1974; Newton \& McKenna, 2007). To be eligible for the fifth group (the "expert" group), participants needed five years of practice in the same clinical domain, as suggested in other studies where 
"experts" were asked to participate (Benner, 2001; Benner, Tanner, \& Chesla, 1992; McHugh \& Lake, 2010; Simmons et al., 2003). Additionally, Pepin, Dubois, Girard, Tardif, and Ha (2011) used the same criteria for their expert group in their study on clinical nursing leadership. In accordance with the usual number of participants used for the think aloud method (Fonteyn \& Fisher, 1995), at least 10 participants per group was planned; in similar studies, researchers recruited from 9 to 16 participants (Fonteyn \& Cahill, 1998; Göransson et al., 2008; Simmons et al., 2003). Data regarding sex, age, previous university studies, academic profiles, and years of experience are presented in Table 1.

Table 1

Information on participants $(n=66)$

\begin{tabular}{|l|l|l|l|l|l|}
\hline Participants & Women/Men & Age range & $\begin{array}{l}\text { Previous } \\
\text { university } \\
\text { studies (N) }\end{array}$ & $\begin{array}{l}\text { Academic } \\
\text { profile (initial } \\
\text { baccalaureate/ } \\
\text { diploma to } \\
\text { baccalaureate/ } \\
\text { diploma) }\end{array}$ & $\begin{array}{l}\text { Years of } \\
\text { experience }\end{array}$ \\
\hline $\begin{array}{l}\mathbf{1}^{\text {st }} \text { year } \\
\text { students }\end{array}$ & $10 / 4$ & $21-35$ & N/A & $11 / 3 / 0$ & N/A \\
\hline $\begin{array}{l}\mathbf{2}^{\text {nd }} \text { year } \\
\text { students }\end{array}$ & $11 / 3$ & $21-45$ & N/A & $12 / 2 / 0$ & $0-1$ \\
\hline $\begin{array}{l}\mathbf{3}^{\text {rd }} \text { year } \\
\text { students }\end{array}$ & $13 / 0$ & $21-45$ & N/A & $6 / 7 / 0$ & $0-3$ \\
\hline New RNs & $11 / 0$ & $21-40$ & 6 & $2 / 4 / 5$ & $1-2$ \\
\hline Expert RNs & $13 / 1$ & $27-58$ & 5 & $3 / 2 / 9$ & $6-35$ years \\
\hline
\end{tabular}

\section{Data collection}

Using patient scenarios, nursing students and RNs were invited to think aloud during individual interviews.

\section{$\underline{\text { Patient scenarios }}$}

The use of patient scenarios is common when gathering data with the think aloud method (Fonteyn et al., 1993; Göransson et al., 2008; Simmons et al., 2003). Following Fonteyn et al.'s (1993) recommendation, patient scenarios were specifically designed to assess CRN and were previously validated in another study (Deschênes, 2006). Thus, these scenarios were relevant to nursing practice and grounded in clinical situations typically encountered by nurses in the workplace; an example is presented in Table 2. Five patient scenarios were used for each participant during one interview session, as suggested in a previous study (Göransson et al., 2008).

The scenarios were presented one at a time to the participants (verbally and in writing), and additional information (prompts) was provided verbally and in writing in order to keep the participants thinking aloud. Participants were asked to explain how specific new information influenced their initial ideas. This process (initial thoughts, adding information, and thinking again) was repeated for the five patient scenarios. 
One research assistant conducted the 66 think aloud interviews. The interviews took place in a university office for the students or at the nurses' workplace; they lasted approximately 60 minutes and were audio-recorded. As recommended by think aloud researchers in other studies (Charters, 2003; Simmons et al., 2003), the research assistant was specially trained to help participants continue to think aloud to ensure the participants would voice as many thoughts as possible during each scenario. Data were collected between September 2009 and September 2010 .

Table 2

Example of one patient scenario used in the study

Mr. Barry had a total hip replacement surgery two days ago. When you try to assist your patient with ambulation, you realise that he is still refusing to move, saying that he is unable to do so. Think aloud.

You also notice that Mr. Barry turns down the help of his wife, who is currently at his bedside. Think aloud.

He also refuses to take an analgesic drug before being mobilised. Think aloud.

\section{Ethical considerations}

Ethics certificates were obtained from the university where the nursing students were recruited and from both hospitals where the RNs were recruited. Informed consent was obtained from each participant before the interview. The confidentiality section of the consent form specifically stated that teachers and employers would not have access to the interviews. Information about the voluntary nature of participation, including the possibility to withdraw without explanation, was provided.

\section{Data analysis}

The 66 interviews were transcribed verbatim and imported to QDA Miner 3.0. Thinking strategies as described by Fonteyn (1998) were used to come up with the categories and subcategories to code the data (see Table 3). As described in similar studies (Fonteyn et al., 1993; Newell \& Simon, 1972; Simmons et al., 2003), data analysis was performed using the three steps of protocol analysis: (1) analysis of sentences, to identify the concepts used by the participant while thinking; (2) analysis of meanings, to describe the links the participant drew between the concepts; and (3) analysis of scripts, to produce a comprehensive description of the participants' reasoning processes. These three steps were performed for the data of each interview. The researchers then used the encoded data to write five descriptive narratives, one per participant group, to highlight the groups' specific reasoning processes. Finally, a comparative text and chart were generated based on the integration and the interpretation of the five narratives, and the CRN's developmental stages could then be identified and differentiated. Once the stages were determined, a review of specific narratives enabled the identification of the critical milestones. This iterative analytic process led to the development of the CRN's cognitive learning model. 
Table 3

Categories and subcategories adapted from Fonteyn's (1998) thinking strategies

\begin{tabular}{|c|c|}
\hline Categories & Subcategories \\
\hline Recognize a pattern & $\begin{array}{ll}\text { - } & \text { Typical case; } \\
\text { - } & \text { Standardized treatment protocol; } \\
\text { - } & \text { Representing a familiar situation; } \\
\text { - } & \text { Representing an unusual situation. }\end{array}$ \\
\hline Order concepts by priority & $\begin{array}{l}\text { - Focusing on an action plan; } \\
\text { - Focusing on the patient's concerns. }\end{array}$ \\
\hline Search for missing information & $\begin{array}{l}\text { - Vital signs; } \\
\text { - Deepen or define an evaluation; } \\
\text { - Logistical information; } \\
\text { - Patient's history; } \\
\text { - Determine nursing care plan; } \\
\text { - Laboratory tests; } \\
\text { - } \text { Medication; } \\
\text { - Resources; } \\
\text { - } \quad \text { Procedures, politics and rights. }\end{array}$ \\
\hline Generate hypotheses & $\begin{array}{l}\text { - Determine the cause; } \\
\text { - Identify illness/health problem; } \\
\text { - Hypothesize on patient's state; } \\
\text { - Identify patient's needs; } \\
\text { - Determine interventions or treatments. }\end{array}$ \\
\hline Predict & $\begin{array}{l}\text { - Interventions; } \\
\text { - Interventions and care results; } \\
\text { - Patient's state; } \\
\text { - Discoveries and laboratory tests; } \\
\text { - Situation; } \\
\text { - Events; } \\
\text { - Patient, colleagues and families' } \\
\text { - } \text { Patient's needs. }\end{array}$ \\
\hline Link information & 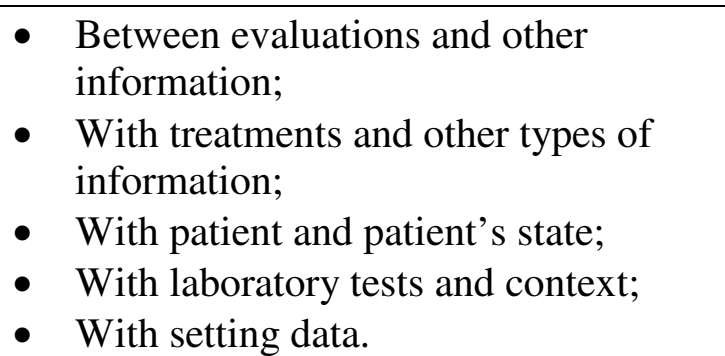 \\
\hline Propose a statement based on a rule & $\begin{array}{l}\text { - } \quad \text { Establish/set aside a problem; } \\
\text { - } \quad \text { Choose an action plan; } \\
\text { - } \quad \text { Determine the cause; }\end{array}$ \\
\hline
\end{tabular}




\begin{tabular}{|c|c|}
\hline & $\begin{array}{l}\text { - Judge intervention or treatment; } \\
\text { - Evaluate data; } \\
\text { - Clarify a policy or procedure. }\end{array}$ \\
\hline State a rule of practice & $\begin{array}{l}\text { - Policy; } \\
\text { - Procedure; } \\
\text { - Precepts or informal rules. }\end{array}$ \\
\hline Make a choice & $\begin{array}{l}\text { - Nursing interventions; } \\
\text { - Actions; } \\
\text { - Treatments; } \\
\text { - Laboratory tests. }\end{array}$ \\
\hline Judge value & $\begin{array}{l}\text { Of evaluation conclusions; } \\
\text { - Of treatments or interventions; } \\
\text { - Of laboratory tests. }\end{array}$ \\
\hline Conclude & $\begin{array}{l}\text { - On patient's state; } \\
\text { - On a situation. }\end{array}$ \\
\hline Provide explanations & $\begin{array}{l}\text { - For treatments; } \\
\text { - For nursing interventions; } \\
\text { - For actions; } \\
\text { - For tests; } \\
\text { - For patient's concerns; } \\
\text { - For predictions. }\end{array}$ \\
\hline Other thinking strategies & $\begin{array}{l}\text { - Pause and think; } \\
\text { - } \text { Qualify and nuance; } \\
\text { - Ask a question; } \\
\text { - Assume; } \\
\text { - Generalize. }\end{array}$ \\
\hline
\end{tabular}

Scientific rigour

To increase the credibility of the results, $15 \%$ of the data analysis was performed independently by two researchers as well as by a trained research assistant. Differences in coding were resolved through discussion. Furthermore, a peer debriefing session was conducted (Given, 2008) with two independent experts in clinical reasoning. Transferability was also addressed, with the methodological choices and processes of the research design being described in substantial detail.

\section{Results}

All the transcribed interviews were coded, which led to a significant amount of data. Results are presented synthetically in the following two sections: (1) results specific to each group; and (2) the cognitive learning model.

\section{Results specific to each group of participants}

The first group of participants, nursing students at the very end of their first year, mainly searched for missing information in order to determine an intervention to help the patient. During the think aloud interview, all of them said they would read the chart, talk with the patient, 
and consult their nursing supervisor and other members of the nursing team. They said that they needed to determine the right interventions so they could inform and reassure the patient about his health condition. It was clear that they all preferred to intervene in the clinical situation rather than cogitate about it.

The second group included nursing students who had completed their second year. The think aloud data showed that these participants were searching for missing information of a scientific nature to justify the interventions they were planning. They also used their previous clinical experiences and the unit's routines to explain their care planning. The patient and family's concerns were the main focus of their information seeking. Furthermore, a few of the participants linked information and generated hypotheses to explain a clinical situation or to suggest interventions. These students also predicted a potential evolution of the clinical situation.

The think aloud data gathered from the third year nursing students suggested that this group was searching for missing information while also ordering concepts by priority and generating hypotheses; these hypotheses were causal and interventional in nature. Their sources of information were the patient and family, the nursing supervisor, and other health care professionals, as well as the patient's chart and the scientific literature.

The fourth group included newly graduated nurses (9-24 months). The think aloud data revealed that these participants were searching for missing information and trying to provide explanations about the clinical situation, but we could not identify any hypothesis generation nor information linking. Great importance was put on proposing a statement based on a rule and stating a rule of practice, these being primarily precepts or informal rules. Thus, these newly graduated nurses relied mostly on routines and protocols to justify their interventions.

As for the fifth group, the "expert" nurses, the think aloud data varied greatly between individuals. A lot of the data showed some participants in this group preferred to propose a statement based on a rule and to state a rule of practice, while others decided to make a choice and provide explanations.

To sum up, the data revealed that across the five stages, students and nurses were preoccupied with doing things to help the patients, and that the interventions were predominantly based on routines and protocols. Their concern appeared to be an impediment to the development of their clinical reasoning. To the question "What goes through your mind when you read this clinical situation?" (see Table 2), they spontaneously verbalized their potential interventions. For example, a first year student (first group) said "I would read the chart to know what I have to do", a second year student (second group) said "I would ask the patient about his needs", while a third year student (third group) said "My priority would be to make sure the patient takes his medication on time." A newly graduated nurse (fourth group) had the same answer as the third year student, whereas an expert nurse (fifth group) revealed that she would explain the relevance of walking after a surgery.

Across all the groups of participants, we noted the deployment of very few cognitive strategies related to CRN. The data also suggested that the generation of hypotheses was hindered and even replaced by both proposing a statement based on a rule and stating a rule of practice when the 
newly graduated nurse entered the clinical world as a professional. Moreover, this phenomenon seemed to persist in some nurses who participated in the study as "experts", which was unanticipated considering their five years of clinical practice in the same setting or field.

\section{Table 4}

Stages and critical milestones

\begin{tabular}{|l|l|}
\hline \multicolumn{1}{|c|}{ Stages } & \multicolumn{1}{|c|}{ Critical milestones } \\
\hline I need to know what to do & $\begin{array}{l}\text { To become conscious of and to } \\
\text { integrate/accept the scientific part of the } \\
\text { nurse's role. }\end{array}$ \\
\hline $\begin{array}{l}\text { I need to justify my interventions using } \\
\text { evidence-based resources }\end{array}$ & $\begin{array}{l}\text { To efficiently use evidence-based literature } \\
\text { in nursing. }\end{array}$ \\
\hline $\begin{array}{l}\text { I adapt my interventions to each clinical } \\
\text { situation }\end{array}$ & $\begin{array}{l}\text { To articulate cognitive operations in order } \\
\text { to link diverse information and generate } \\
\text { hypotheses. }\end{array}$ \\
\hline $\begin{array}{l}\text { I adapt my interventions to the unit's } \\
\text { routines }\end{array}$ & $\begin{array}{l}\text { To critically integrate the unit's routines } \\
\text { and protocols. }\end{array}$ \\
\hline $\begin{array}{l}\text { I adapt my interventions to a specific } \\
\text { nursing domain }\end{array}$ & To master a nursing domain. \\
\hline
\end{tabular}

A cognitive learning model of clinical reasoning in nursing

Table 4 presents the five stages of the resulting cognitive learning model of CRN and the critical milestones for each of these stages. The five-stage model was elaborated with a corresponding critical milestone. The name of each stage is based on the researchers' interpretation of the think aloud data, focusing on doing something for the patient, which was prevalent within the verbatim of both the students and nurses. The milestones emerged from the researchers' discussions and particularly from their expertise in education. Figure 1 is an illustration of the model, representing the intricate and continuous development of the competency. 


\section{Figure 1}

A cognitive learning model of clinical reasoning in nursing

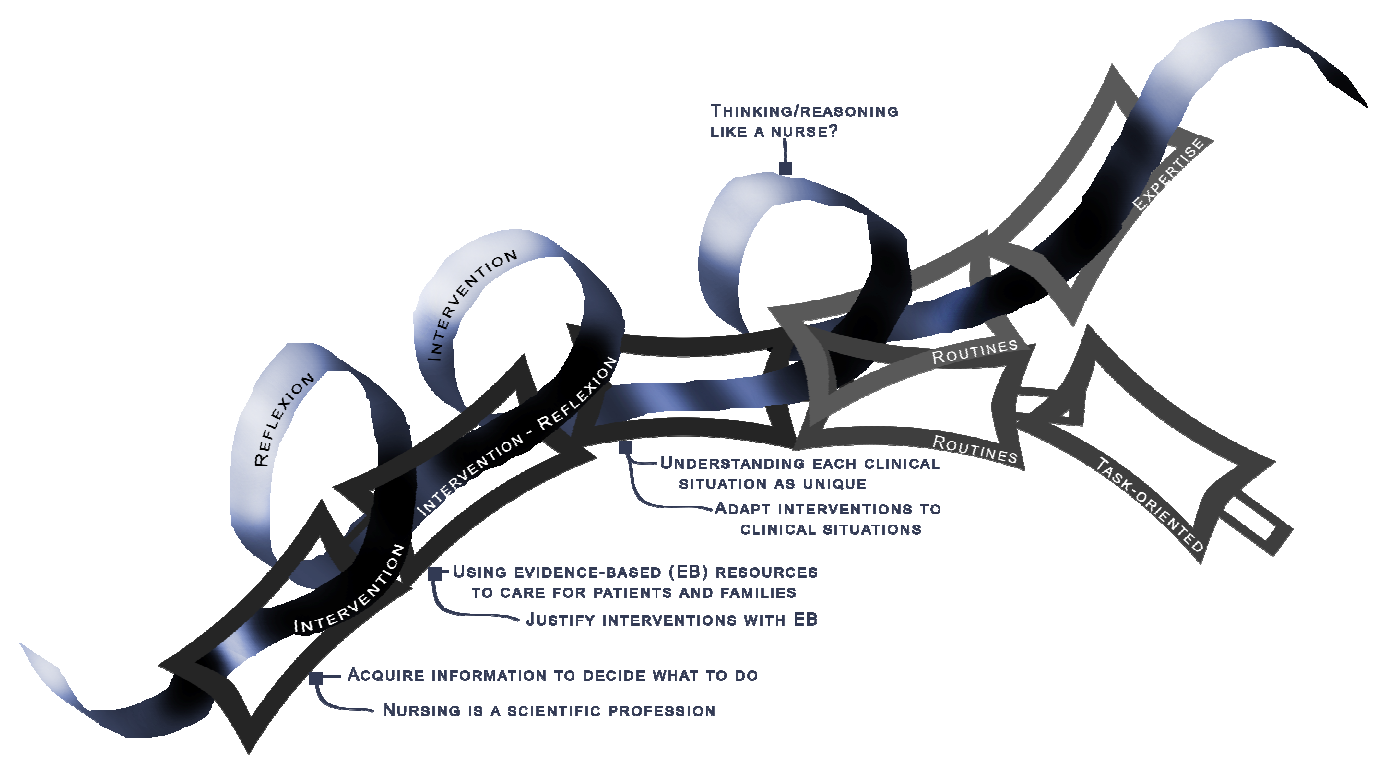

\section{Limitations}

This study has some limitations. First, the three groups of students all came from the same program (university; competency-based approach), while the two groups of RNs graduated from different programs, some at the college level, some at the university level. This jeopardized the issue of the developmental continuity from before to after graduation. This limitation was discussed with the clinical partners involved in the planning of the study at the very beginning of the research process. The research team subsequently decided that it was crucial to get an accurate description of how CRN was addressed in their institutions. As for the second limitation, the group of experts was very heterogeneous, as they all came from different academic programs and had different career trajectories. Some were experts in a very specific domain (e.g. pediatrics), while others had experience in more general domains like medicine and surgery. These differences may have contributed to the two-sided cognitive learning model.

\section{Discussion}

The cognitive learning model of CRN that emerged from the data analysis of this study corresponds to the NRC (2001) and Tardif's definition (2006) of a cognitive learning model. The stages are distinct and complement each other, and they all build on the preceding ones. One surprising characteristic of this cognitive learning model is the two-way potential progression of CRN after graduation: to the expertise, as Benner (2001) described it, versus to a task-oriented practice. Another interesting element is the recognition of the crucial importance of the scientific aspect of the nursing role with the integration of evidence-based resources and hypothesis generation as critical milestones in the development of CRN. We argue that strengthening both these critical milestones in the pre- and post-registration of nurses would guarantee stronger CRN. 
Strengthening the teaching and learning of the scientific aspect of nursing

The results show that one main obstacle to the development of CRN appears to be the urge to do things to help patients, and that this urge is present from the beginning of nursing education and seems to be reinforced after graduation. However, it is essential for nursing students and RNs to understand the importance of thinking and reasoning in nursing rather than limiting their practice to tasks. This led us to the first critical milestone in the development of CRN, that is, the solid awareness and appropriation of the scientific component of the nursing role. Nursing students learn chemistry, human biology, pathophysiology, pharmacology, mathematics, nutrition, developmental psychology, and sociology, among others. Additionally, they learn the nursing process, nursing theories, leadership skills, technical procedures, and nursing interventions. Paley, Cheyne, Dalgleish, Duncan, and Niven (2007, p. 692) said: "Scientific reasoning and evidence-based knowledge have epistemological priority over the other forms of nursing knowledge." As stated in Benner's book (2010), we argue that nursing educators should rely on integrative educational approaches and strategies to support nursing students in learning diverse forms of nursing knowledge. Thus, we recommend using clinical situations in the classroom (e.g. PBL, narrative pedagogy, simulations, etc.) that are significant for the students and transferable to clinical settings (Tardif, 2006). Also, we advocate that the scientific basis of nursing needs to be nurtured, explained, discussed, and confronted, perhaps with nursing students observing the day-to-day practice of mentors in clinical units (e.g. reflexive practice, expert panels, etc.).

\section{Strengthening the teaching and learning of hypothesis generation}

The results of our study show that the process of generating hypotheses appears late in nursing education and that it is easily interrupted when newly graduated nurses enter the work place. Moreover, newly graduated nurses and experts did not resort very much to hypothesis generation. Considering that hypothesis generation is a central cognitive operation in clinical reasoning (Fonteyn \& Cahill, 1998), why is it not used by RNs? How do we explain that the nursing students who participated in our study did not generate as many explanatory or interventional hypotheses as were expected of them? Is it that we, as nursing educators, are overlooking hypothesis generation? We suggest that nursing educators should consider integrating the nursing process in problem-based learning (PBL; Rideout, 2001), simulation with debriefing (Jeffries, 2012), and reflective practice (Tanner, 2006). Again, in their book Educating nurses: a call for radical transformation, Benner et al. (2010) describe strategies that would also contribute to hypothesis generation and more reflection by nursing students. Along the same lines, and as Frenk et al. emphasize in their international expert report (2010), there is a very real need for health professionals in education programs to develop competencies, meaning to adopt a competency-based approach [name withheld to maintain the integrity of the review process]. Moreover, we believe it is necessary to rethink the orientation programs and the continuing education of experienced nurses, by developing programs that use competency-based approaches. Henceforth, continuing education should focus on nursing processes and reflective practices as much as on routines and protocols.

\section{Implications}

This study is an invitation to nursing educators to help nursing students and RNs to acknowledge the scientific aspect of the nursing role. As such, they could help their learners become aware of the cognitive strategies underlying CRN, especially where generating hypotheses is concerned. 
They should also pay attention to their learners' clinical experience when their struggle to master routines and protocols becomes of central importance. Thus, continuing education should support all nurses in the development of CRN, as much as it currently supports the learning of new technologies, routines, and protocols.

There are several implications for nursing education researchers. First, the CRN cognitive learning model should be put to the test and used as a guide for teaching and evaluating CRN in different contexts. It would also be of utmost importance to elaborate more cognitive learning models from other sources, such as students and RNs from the same pre-registration program or from different types of pre-registration programs. It would also be of interest to conduct a longitudinal study with one cohort of students/RNs. Moreover, further experimental studies could focus on different pedagogical approaches and strategies and their impact on the development of CRN, based on cognitive learning models.

\section{Conclusion}

We encourage a "virtuous cycle", specifically that if a nurse's practice comes from a scientific perspective, she will generate hypotheses from her data gathering and interpretation, and consequently she will adapt her practice to every clinical situation, allowing her to share this role enactment with her colleagues and students. 


\section{References}

Adams, B. L. (2003). Making clinical decisions: Baccalaureate nursing student thought processes (Doctoral dissertation). Available from ProQuest Dissertations and Theses database. (UMI No. 3106754)

American Association of Colleges of Nursing. (2008). The essentials of baccalaureate education for professional nursing practice. Retrieved from http://www.aacn.nche.edu/educationresources/BaccEssentials08.pdf

Andersson, N., Caderfjäll, C., Jylli, L., Kajermo, K. N., \& Klang, B. (2007). Professional roles and research utilization in paediatric care: Newly graduated nurses experiences. Scandinavian Journal of Caring Sciences, 21, 91-97. doi: 10.1111/j.1471-6712.2007.00435.x

Andersson, N., Klang, B., \& Petersson, G. (2012). Differences in clinical reasoning among nurses working in highly specialised paediatric care. Journal of Clinical Nursing, 21, 870879. doi: 10.1111/j.1365-2702.2011.03935.x

Banning, M. (2008). Clinical reasoning and its application to nursing: Concepts and research studies. Nursing Education in Practice, 8, 177-183. doi: 10.1016/j.nepr.2007.06.004

Bartels, J. E., \& Bednash, G. (2005). Anwsering the call for quality nursing care and patient safety: A new model for nursing education. Nursing Administration Quarterly, 29, 5-13. Retrieved from http://journals.lww.com/naqjournal/pages/default.aspx

Benner, P. (2001). From novice to expert: excellence and power in clinical nursing practice. Upper Saddle River, NJ: Prentice Hall.

Benner, P., Sheets, V., Uris, P., Malloch, K., Schwed, K., \& Jamison, D. (2002). Individual, practice, and system causes of errors in nursing: A taxonomy. Journal of Nursing Administration, 32, 509-523. doi: 10.1097/00005110-200210000-00006

Benner, P., Sutphen, M., Leonard, V., \& Day, L. (2010). Educating nurses: a call for radical transformation. San Francisco, CA: Jossey-Bass.

Benner, P., Tanner, C., \& Chesla, C. (1992). From beginner to expert: gaining a differentiated clinical world in critical care nursing. Advances in Nursing Science, 14, 13-28. Retrieved from http://journals.lww.com/advancesinnursingscience/pages/default.aspx

Burns, N., \& Grove, S. K. (2009). The practice of nursing research: appraisal, synthesis, and generation of evidence (6 ed.). Saint-Louis, MO: Saunders/Elsevier.

Casey, K., Fink, R., Krugman, M., \& Propst, J. (2004). The graduate nurse experience. Journal of Nursing Administration, 34, 303-311. doi: 10.1097/00005110-200406000-00010

Charters, E. (2003). The use of think-aloud methods in qualitative research: an introduction to think-aloud methods. Brock Education, 12(2), 68-82. Retrieved from http://brocked.ed.brocku.ca/

Chernomas, W. M., Care, W. D., McKenzie, J.-A. L., Guse, L., \& Currie, J. (2010). "Hit the ground running": Perspectives of new nurses and nurse managers on role transition and integration of new graduates. Canadian Journal of Nursing Leadership, 22(4), 70-86. doi: $10.12927 /$ cjnl.2010.21598 
Corcoran, S., Narayan, S., \& Moreland, H. (1988). "Thinking aloud" as a strategy to improve clinical decision making. Heart \& Lung: The Journal of Critical Care, 17, 463-468. Retrieved from http://www.heartandlung.org/

del Bueno, D. (2005). A crisis in critical thinking. Nursing Education Perspectives, 26, 278-282. doi: 10.1043/1536-5026(2005)026[0278:ACICT]2.0.CO;2

Deschênes, M.-F. (2006). Élaboration et évaluation des propriétés psychométriques d'un instrument d'évaluation du raisonnement clinique empreint de Human Caring (Unpublished master's thesis). Université de Montréal, Montréal, Québec.

Duchscher, J. E. B. (2008). A process of becoming: The stages of new nursing graduate professional role transition. The Journal of Continuing Education in Nursing, 39, 441-450. doi: 10.3928/00220124-20081001-03

Duchscher, J. E. B. (2009). Transition shock: The initial stage of role adaptation for newly graduated registered nurses. Journal of Advanced Nursing, 65, 1103-1113. doi: 10.1111/j.1365-2648.2008.04898.x

Duchscher, J. E. B., \& Cowin, L. S. (2004). The experience of marginalization in new nursing graduates. Nursing Outlook, 52, 289-296. doi: 10.1016/j.outlook.2004.06.007

Duff, B., Gardiner, G., \& Barnes, M. (2007). The impact of surgical ward nurses practising respiratory assessment on positive patient outcomes. Australian Journal of Advanced Nursing, 24(4), 52-56. Retrieved from http://www.ajan.com.au/

Dyess, S. M., \& Sherman, R. O. (2009). The first year of practice: New graduate nurses' transition and learning needs. The Journal of Continuing Education in Nursing, 40, 403-410. doi: 10.3928/00220124-20090824-03

Eisenhauer, L. A., Hurley, A. C., \& Dolan, N. (2007). Nurses' reported thinking during medication administration. Journal of Nursing Scholarship, 39, 82-87. doi: 10.111/j.15475069.2007.00148.x

Elizondo-Omanã, R. E., Morales-Gómez, J. A., Morquecho-Espinoza, O., Hinojosa-Amaya, J. M., Villarreal-Silva, E. E., García-Rodríguez, M. d. 1. A., \& Guzmán-López, S. (2010). Teaching skills to promote clinical reasoning in early basic science courses. Anatomical Sciences Education, 3, 267-271. doi: 10.1002/ase.178

Ericsson, K. A., \& Simon, H. A. (1980). Verbal reports as data. Psychological Review, 87, 215251. doi: 10.1037/0033-295X.87.3.215

Fero, L. J., Witsberger, C. M., Wesmiller, S. W., Zullo, T. G., \& Hoffman, L. A. (2009). Critical thinking ability of new graduate and experienced nurses. Journal of Advanced Nursing, 65, 139-148. doi: 10.1111/j.1365-2648.2008.04834.x

Fonteyn, M. E. (1998). Thinking strategies for nursing practice. Philadelphia, PA: Lippincott.

Fonteyn, M. E., \& Cahill, M. (1998). The use of clinical logs to improve nursing students' metacognition: A pilot study. Journal of Advanced Nursing, 28. doi: 10.1046/j.13652648.1998.00777.x 
Fonteyn, M. E., \& Fisher, A. (1995). Use of think aloud method to study nurses reasoning and decision making in clinical practice settings. Journal of Neuroscience Nursing, 27, 124-128. Retrieved from http://journals.lww.com/jnnonline/pages/default.aspx

Fonteyn, M. E., Kuipers, B., \& Grobe, S. J. (1993). A description of think aloud method and protocol analysis. Qualitative Health Research, 3, 430-441. doi: 10.1177/104973239300300403

Fonteyn, M. E., \& Ritter, B. J. (2008). Clinical reasoning in nursing. Dans J. Higgs, M. A. Jones, S. Loftus \& N. Christensen (Eds.), Clinical reasoning in the health professions (3rd ed., pp. 235-244). Oxford, United Kingdom: Butterworth-Heinemann.

Forsberg, E., Georg, C., Ziegert, K., \& Fors, U. (2011). Virtual patients for assessment of clinical reasoning in nursing - a pilot study. Nurse Education Today, 31, 757-762. doi: 10.1016/j.nedt.2010.11.015

Fowler, L. P. (1997). Clinical reasoning strategies used during care planning. Clinical Nursing Research, 6, 349-361. doi: 10.1177/105477389700600405

Frenk, J., Chen, L., Bhutta, Z. A., Cohe, J., Cris, N., Evan, T., . . Z Zurayk, H. (2010). Health professionals for a new century: transforming education to strengthen health systems in an interdependant world. The Lancet, 376(9756), 1923-1958. doi: 10.1016/S01406736(10)61854-5

Funkesson, K. H., Anbäcken, E.-M., \& Ek, A.-C. (2007). Nurses' reasoning process during care planning taking pressure ulcer prevention as an example. A think-aloud study. International Journal of Nursing Studies, 44, 1109-1119. doi: 10.1016/j.ijnurstu.2006.04.016

Given, L. M. (2008). The SAGE Encyclopedia of Qualitative Research Methods. Thousand Oaks, CA: SAGE.

Gonczi, A. (1996). Reconceptualising competency-based education and training: With particular reference to education for occupations in Australia (Doctoral thesis, University of Technology, Sydney, Australia). Retrieved from http://epress.lib.uts.edu.au/research/bitstream/handle/10453/20143/02wholelinkingessay.pdf

Göransson, K. E., Ehnfors, M., Fonteyn, M. E., \& Ehrenberg, A. (2008). Thinking strategies used by registered nurses during emergency department triage. Journal of Advanced Nursing, 61. doi: 10.1111/j.1365-2648.2007.04473.x

Greenwood, J. (2000). Critique of the graduate nurse: An international perspective. Nurse Education Today, 20, 17-23. doi: 10.1054/nedt.2000.0424

Greenwood, J., Sullivan, J., Spence, K., \& McDonald, M. (2000). Nursing scripts and the organizational influences on critical thinking: Report of a study of neonatal nurses' clinical reasoning. Journal of Advanced Nursing, 31, 1106-1114. doi: 10.1046/j.13652648.2000.01378.x

Grobe, S. J., Drew, J. A., \& Fonteyn, M. E. (1991). A descriptive analysis of experienced nurses clinical reasoning during a planning task. Research in Nursing \& Health, 14, 305-314. doi: 10.1002/nur.4770140409 
Hannes, K., Vandermissen, J., De Blaeser, L., Peeters, G., Goedhuys, J., \& Aertgeerts, B. (2007). Barriers to evidence-based nursing: A focus group study. Journal of Advanced Nursing, 60, 162-171. doi: 10.1111/j.1365-2648.2007.04389.x

Hansen, J. L. (2008). Assessing the efficacy of a precepted orientation in new graduate nurses' transition into the workplace (Master's thesis). Available from ProQuest Dissertations and Theses database. (UMI No. 1465140)

Jeffries, P. R. (2012). Simulation in nursing education: from conceptualization to evaluation (2 ed.). New York, NY: National League for Nursing.

King, L., \& Clark, J. M. (2002). Intuition and the development of expertise in surgical ward and intensive care nurses. Journal of Advanced Nursing, 37, 322-329. doi: 10.1046/j.13652648.2002.02105.x

Kramer, M. (1974). Reality shock: Why nurses leave nursing. Saint Louis, MO: C.V. Mosby.

MacNeela, P., Clinton, G., Place, C., Scott, A., Treacy, P., Hyde, A., \& Dowd, H. (2010). Psychosocial care in mental health nursing: A think aloud study. Journal of Advanced Nursing, 66, 1297-1307. doi: 10.111/j.1365-2648.2009.05245.x

Manias, E., Aitken, R., \& Dunning, T. (2004). Decision-making models used by 'graduate nurses' managing patients' medications. Journal of Avanced Nursing, 43, 270-278. doi: 10.111/j.1365.2648.2004.03091.x

McHugh, M. D., \& Lake, E. T. (2010). Understanding clinical expertise: nurse education, experience, and the hospital context. Research in Nursing \& Health, 33, 276-287. doi: 10.1002/nur.20388

National League for Nursing. (s. d.). Competencies for graduates of baccalaureate programs Retrieved from http://www.nln.org/facultyprograms/competencies/comp_bacc.htm

National Research Council. (2001). Knowing what students know. The science and design of educational assessment. Washington, DC: National Academy Press.

Newell, A., \& Simon, H. A. (1972). Human problem solving. Englewood Cliffs, NJ: PrenticeHall.

Newton, J. M., \& McKenna, L. (2007). The transitional journey through the graduate year: A focus group study. International Journal of Nursing Studies, 44, 1231-1237. doi: 10.1016/j.ijnurstu.2006.05.017

O'Neil, E. H., \& Pew Health Professions Commission. (1998). Recreating health professional practice for a new century: the fourth report of the Pew Health Professions Commission. San Francisco, CA: Author.

Oermann, M. H., \& Garvin, M. F. (2002). Stresses and challenges for new graduates in hospitals. Nurse Education Today, 22, 225-230. doi: 10.1054/NEDT.2001.0695

Paley, J., Cheyne, H., Dalgleish, L., Duncan, E. A. S., \& Niven, C. A. (2007). Nursing's ways of knowing and dual process theories of cognition. Journal of Advanced Nursing, 60, 692-701. doi: 10.111/j.1365.2648.2007.04478.x 
Pepin, J., Dubois, S., Girard, F., Tardif, J., \& Ha, L. (2011). A cognitive learning model of clinical nursing leadership. Nurse Education Today, 31, 268-273. doi: 10.1016/j.nedt.2010.11.009

Profetto-McGrath, J. (2005). Critical thinking and evidence-based practice. Journal of Professional Nursing, 21, 364-371. doi: 10.1016/j.profnurs.2005.10.002

Rideout, E. (2001). Transforming nursing education through problem-based learning. Sudbury, MA: Jones and Bartlett.

Schoessler, M., \& Waldo, M. (2006a). The first 18 months in practice: a developmental transition model for the newly graduated nurse. Journal for Nurses in Staff Development, 22, 47-54. Retrieved from http://journals.lww.com/jnsdonline/pages/default.aspx

Schoessler, M., \& Waldo, M. (2006b). Organizational infrastructure to support development of newly graduated nurses. Journal for Nurses in Staff Development, 22, 286-293. Retrieved from http://journals.lww.com/jnsdonline/pages/default.aspx

Shin, K. R. (1998). Critical thinking ability and clinical decision-making skills among senior nursing students in associate and baccalaureate programmes in Korea. Journal of Advanced Nursing, 27, 414-418. doi: 10.1046/j.1365-2648.1998.00499.x

Simmons, B. (2010). Clinical reasoning: Concept analysis. Journal of Advanced Nursing, 66, 1151-1558. doi: 10.111/J.1365-2648.2010.05262.x

Simmons, B., Lanuza, D., Fonteyn, M., Hicks, F., \& Holm, K. (2003). Clinical reasoning in experienced nurses. Western Journal of Nursing Research, 25, 701-719. doi: $10.1177 / 0193945903253092$

Standing, M. (2007). Clinical decision-making skills on the developmental journey from student to registered Nurse: A longitudinal inquiry. Journal of Advanced Nursing, 60, 257-269. doi: 10.1111/j.1365-2648.2007.04407.x

Tanner, C. A. (2006). Thinking like a nurse: a research-based model of clinical judgment in nursing. Journal of Nursing Education, 45, 204-211. Retrieved from http://www.healio.com/journals/JNE

Tardif, J. (2006). L'évaluation des compétences. Documenter le parcours de développement. Montréal, Québec: Chenelière Éducation.

Task Force on the Essential Patient Safety Competencies for Professional Nursing Care. (2006). Hallmarks of quality and patient safety: Recommended baccalaureate competencies and curricular guidelines to ensure high-quality and safe patient care. Journal of Professional Nursing, 22, 329-330. doi: 10.1016/j.profnurs.2006.10.005

Thompson, C., Bucknall, T., Estabrookes, C. A., de Vos, R., Binnecade, J., Barrat, G., \& Saunders, J. (2007). Nurses' critical event risk assessments: A judgement analysis. Journal of Clinical Nursing, 18, 601-612. doi: 10.1111/j.1365-2702.2007.02191.x

Victor-Chmil, J. (2013). Critical thinking versus clinical reasoning versus clinical judgment. Nurse Educator, 38, 34-36. doi: 10.1097/NNE.0b013e318276dfbe

Villeneuve, M. J., \& MacDonald, J. A. T. (2006). Vers 2020 : visions pour les soins infirmiers. Ottawa, Ontario: Association des infirmières et infirmiers du Canada. 
Quality Advancement in Nursing Education - Avancées en formation infirmière, Vol. 1, Iss. 1 [2014], Art. 4

Woods, A., \& Doan-Johnson, S. (2002). Toward a taxonomy of nursing practice errors. Nursing Management, $\quad 33(10), \quad 45-48 . \quad$ Retrieved from http://journals.lww.com/nursingmanagement/Pages/default.aspx 